\title{
The epidemiology of carbapenem
} resistance in Acinetobacter baumannii complex in Germany (2014-2018): an analysis of data from the national Antimicrobial Resistance Surveillance system

\author{
Dunja Said ${ }^{1}$, Niklas Willrich' ${ }^{1}$ Olaniyi Ayobami ${ }^{1}$, Ines Noll ${ }^{1}$, Tim Eckmanns ${ }^{1}$ and Robby Markwart ${ }^{1,2^{*}}$ (B)
}

\begin{abstract}
Background: Carbapenem-resistant Acinetobacter baumannii complex (CRABC) has globally emerged as a serious public health challenge. This study aimed to describe epidemiological trends and risk factors of carbapenem resistance in A. baumannii complex isolates in Germany between 2014 and 2018.

Methods: We analysed 43,948 clinical A. baumannii complex isolates using 2014 to 2018 data from the German Antimicrobial Resistance Surveillance system. We applied descriptive statistics and uni- and multivariable regression analyses to investigate carbapenem resistance in A. baumannii complex isolates.
\end{abstract}

Results: The proportion of carbapenem resistance in clinical A. baumannii complex isolates declined from 7.6\% (95\% confidence interval [95\% Cl] 4.4-12.7\%) in 2014 to 3.5\% (95\% Cl 2.5-4.7\%) in 2018 (adjusted OR [aOR] 0.85 [95\% Cl $0.79-0.93, p \leq 0.001])$. Higher mean CRABC proportions for 2014 to 2018 were observed in secondary care hospitals (4.9\% [95\% Cl 3.2-7.5\%], aOR 3.6 [95\% Cl 2.4-5.3, $p \leq 0.001]$ ) and tertiary care hospitals (5.9\% [95\% Cl 3.0-11.2\%], aOR 5.4 [95\% Cl 2.9-10.0, $p \leq 0.001)$ compared to outpatient clinics (1.3\% [95\% Cl 1.1-1.6\%]). CRABC proportions in hospitals varied between German regions and ranged between $2.4 \%(95 \% \mathrm{Cl} 1.6-3.5 \%)$ in the Southeast and 8.8\% (95\% Cl 4.2-17.3\%) in the Northwest. Lower CRABC proportions were observed in younger patients ( $<1$ year: $0.6 \%$ [95\% Cl 0.2-1.3\%]; $1-19$ years: $1.3 \%$ [95\% Cl 0.7-2.5\%]) than adults (20-39 years: $7.7 \%$ [95\% Cl 4.4-13.0\%]; $40-59$ years: $6.2 \%$ [4.2-8.9\%]; 60-79 years: $5.8 \%$ [95\% Cl 4.0-8.3\%]). In the 20-39 year old patient age group, CRABC proportions were significantly higher for men than for women (14.6\% [95\% Cl 8.6-23.6\%] vs. 2.5\% [95\% Cl 1.3-4.5\%]). A. baumannii complex isolates from lower respiratory infections were more likely to be carbapenem-resistant than isolates from upper respiratory infections (11.4\% [95\% Cl 7.9-16.2\%] vs. 4.0\% [95\% Cl 2.7-6.0\%]; adjusted OR: 1.5 [95\% Cl 1.2-1.9, $p \leq 0.001])$.

Conclusions: In contrast to many other regions worldwide, carbapenem resistance proportions among clinical $A$. baumannii complex isolates are relatively low in Germany and have declined in the last few years. Ongoing efforts in

\footnotetext{
*Correspondence: robby.markwart@med.uni-jena.de

1 Department 3: Infectious Disease Epidemiology, Unit 37: Healthcare Associated Infections, Surveillance of Antibiotic Resistance and Consumption, Robert Koch Institute, Nordufer 20, 13353 Berlin, Germany

Full list of author information is available at the end of the article
} permits use, sharing, adaptation, distribution and reproduction in any medium or format, as long as you give appropriate credit to the original author(s) and the source, provide a link to the Creative Commons licence, and indicate if changes were made. The images or other third party material in this article are included in the article's Creative Commons licence, unless indicated otherwise in a credit line to the material. If material is not included in the article's Creative Commons licence and your intended use is not permitted by statutory regulation or exceeds the permitted use, you will need to obtain permission directly from the copyright holder. To view a copy of this licence, visit http://creativecommons.org/licenses/by/4.0/. The Creative Commons Public Domain Dedication waiver (http://creativeco mmons.org/publicdomain/zero/1.0/) applies to the data made available in this article, unless otherwise stated in a credit line to the data. 
antibiotic stewardship and infection prevention and control are needed to prevent the spread of carbapenem-resistant A. baumannii complex in Germany.

Keywords: Acinetobacter baumannii complex, Carbapenem resistance, Antimicrobial resistance, Surveillance, Epidemiology, ARS

\section{Background}

Acinetobacter baumannii complex (A. baumannii complex) is a group of closely related, ubiquitous, Gram-negative coccobacilli of the Acinetobacter genus. It includes Acinetobacter baumannii, Acinetobacter pittii, Acinetobacter nosocomialis and Acinetobacter calcoaceticus [1, 2]. Among the 60 known Acinetobacter species [3], pathogens of the A. baumannii complex are the most clinically relevant [4] since they cause a number of diseases, such as hospital- and community-acquired pneumonia and bloodstream, skin and soft tissue, and urinary tract infections [4]. A. baumannii complex received a lot of public attention in the United States in particular, since these pathogens were highly prevalent in infections amongst military staff based in Iraq between 2003 and $2005[5,6]$. Due to their environmental persistence [79], species of the A. baumannii complex are particularly known as frequent causes of healthcare-associated infections, especially in intensive care units (ICUs) [10-12].

Members of the A. baumannii complex have developed both intrinsic and acquired resistance against many common antibiotics, such as penicillins, cephalosporins and aminoglycosides. Therefore, carbapenems have become important treatment options for infections with A. baumannii complex [13]. However, after they have been increasingly reported since the early 1990s [14-17], carbapenem-resistant $A$. baumannii complex species have emerged worldwide over the last decades [18-20]. Carbapenem-resistant $A$. baumannii sensu stricto have been shown to be significantly associated with increased mortality [21] and prolonged hospital stays [22]. A recent study by Cassini et al. [23] estimated that approximately 27,000 infections and 2300 deaths in 2015 were caused by carbapenem-resistant Acinetobacter species in countries in the European Union and European Economic Area. The World Health Organization (WHO) and the Centre for Disease Control (CDC) both separately ranked carbapenem-resistant $A$. baumannii as a high priority antibiotic-resistant pathogen [24, 25].

According to the European Antimicrobial Resistance Surveillance Network (EARS-Net), carbapenem resistance in Acinetobacter species from invasive infections in Germany varied between $6.5 \%$ in 2016 and $4.4 \%$ in 2018 [26]. However, there is a lack of studies that systematically investigate the current national epidemiology of carbapenem resistance in species of the
A. baumannii complex. This study therefore aims to provide a comprehensive analysis of epidemiological trends of carbapenem-resistant Acinetobacter baumannii complex (CRABC) in Germany and seeks to identify possible risk factors that are associated with this resistance. A. baumannii complex was analysed, instead of $A$. baumannii sensu stricto, because treatment decisions are often based on A. baumannii complex infection diagnoses, as a result of many laboratories not differentiating $A$. baumannii complex by species level in routine microbiological diagnostics.

\section{Methods \\ Outcomes, study design and the German Antibiotic Resistance Surveillance system}

The primary outcome is the proportion of carbapenemresistant $A$. baumannii complex isolates among all $A$. baumannii complex isolates tested for carbapenem resistance. Additionally, we analysed factors that are associated with the likelihood of carbapenem resistance in A. baumannii complex isolates (see "Study variables" section below).

The secondary outcomes of interest are (1) the proportion of carbapenem-resistant non-baumannii complex Acinetobacter isolates among all non-baumannii complex Acinetobacter isolates tested for carbapenem resistance and (2) the proportional distribution of $A$. baumannii complex species among all Acinetobacter species in different clinical specimen materials.

We performed a retrospective observational study using data from the German Antibiotic Resistance Surveillance (ARS) system between 2014 and 2018. Laboratories that voluntarily participate in the surveillance system submit routine clinical microbiological data to the Robert Koch Institute (RKI) [27]. These data include results from pathogen identification and antimicrobial susceptibility testing, as well as pseudonymised information on health care facilities and patient characteristics, such as care setting type, hospital ward, age, gender, specimen materials and the geographical location of patient care [28]. Forty-eight laboratories contributed to the ARS system in 2018, which includes data from around 13\% of all hospitals (389 out of 3000 ) and around $16 \%$ of all outpatient clinics $(16,016$ out of $\sim 100,000)$ in Germany [29]. 


\section{Selection of Acinetobacter isolates}

Isolates obtained between 2014 and 2018 were selected for the primary analysis. We avoided including multiple isolates from individual patients' single infection episodes by selecting only the patients' first isolate per specimen and per quarter. Since this analysis focuses on clinical infections, isolates derived for multidrug-resistant pathogen screening were also excluded.

For the main analysis, we included all Acinetobacter species isolates that are part of the A. baumannii complex (i.e. A. baumannii, A. pittii, A. calcoaceticus and A. nosocomalis). In addition, we only selected isolates that were tested against at least one of the following carbapenems: meropenem, imipenem, and doripenem. Ertapenem was not selected since it has a considerably different pharmacology compared to the selected carbapenems [30]. We defined an isolate as carbapenem-resistant if it was tested as "resistant" (R) to at least one of the carbapenems of interest based on the standards used in the participating laboratories, such as the guidelines of the European Committee on Antimicrobial Susceptibility Testing (EUCAST) or the Clinical and Laboratory Standards Institute (CLSI). In order to determine proportions of carbapenem resistance among non-baumannii complex Acinetobacter species, isolates from the respective species were included but the same selection criteria were otherwise used as described above.

For the analysis of the proportional distribution of $A$. baumannii complex and non-baumannii complex Acinetobacter species, only isolates that were identified at species level were included. Since complete species identification results were increasingly available after 2014, we only selected isolates from 2015 to 2018 for this analysis. In this analysis, we also included isolates without carbapenem testing.

\section{Study variables}

Carbapenem resistance was analysed for the following variables: care setting type, year of sampling, region in Germany, age, gender and, clinical specimen materials. We grouped care setting type into the following categories: outpatient clinics (primary healthcare facilities), secondary care hospitals (offering basic and standard care), tertiary care hospitals (offering maximum care, such as university hospitals), specialist care hospitals (offering specialised care or private hospitals), prevention and rehabilitation care centres, and other hospitals (offering psychiatric, neurological and/or geriatric care only). Clinical specimen materials were categorised into the following groups: wound (swabs from wounds and abscesses), blood (blood cultures), urine (urine samples), upper respiratory materials (swabs from the upper respiratory tract), lower respiratory materials (bronchial lavage, bronchial secretion, bronchial rinse water, sputum and tracheal secretion), and other specimens that did not fit in the categories listed above (i.e. swabs, biopsy tissues, dialysate material, ejaculate, skin flakes, hair and nails, catheter, cerebrospinal fluid, puncture material, stool samples and non-specified materials). We grouped patient gender into female and male and categorised patient ages in six different groups $(<1,1-19,20-39$, $40-59,60-79, \geq 80$ years). Furthermore, to determine the isolate's geographical origin (location of the healthcare facility), each of the federal states was categorised into one of five major regions in Germany: Northeast (Mecklenburg-West Pomerania, Brandenburg, Berlin, Saxony-Anhalt), Southeast (Bavaria, Saxony, Thuringia), Southwest (Hesse, Rhineland-Palatinate, Saarland, Baden-Wurttemberg), West (North Rhine-Westphalia) and Northwest (Bremen, Lower Saxony, Hamburg, Schleswig-Holstein). We considered all variables as categorical for statistical analyses, apart from year, which was treated as a continuous variable.

\section{Statistical analyses}

All statistical analyses were performed using $\mathrm{R}$ version 3.6.1 [31] and the "survey" package (version 3.37) [32]. We used percentages with $95 \%$ confidence intervals (95\% CI) to describe proportions of carbapenem-resistant isolates among all isolates tested against carbapenems. Univariable and multivariable logistic regression models were performed to identify patient and healthcarerelated risk factors that are associated with carbapenem resistance in isolates from patients with $A$. baumannii complex infections. All previously listed variables were included in the univariable and the multivariable logistic regression model. We accounted for clustering at facility level in the carbapenem resistance proportions calculations and the analysis of associations between carbapenem resistance and the selected variables.

\section{Results \\ Baseline characteristics}

In total, 43,948 isolates from 12,169 and 26,840 patient visits in outpatient clinics and hospitals, respectively, were included in the primary analysis (Table 1). The number of isolates collected increased from 2014 to 2017, reflecting the increasing coverage of the ARS database. Almost half (45.4\%) of the analysed A. baumannii complex isolates were from female patients, while $36.1 \%$ were from male patients. For $18.4 \%$ of all isolates the patient gender was unknown. Most isolates were collected from people in older age groups (median: 69 years, IQR: 52-79). A. baumannii complex isolates derived most frequently from wounds $(27.9 \%)$, 
Table 1 Baseline characteristics of Acinetobacter baumannii complex isolates analysed in this study

\begin{tabular}{|c|c|c|c|c|c|c|}
\hline & $\begin{array}{l}\text { Number of isolates } \\
\text { (total) }\end{array}$ & (\%) & $\begin{array}{l}\text { Number of carbapenem- } \\
\text { resistant isolates }\end{array}$ & (\%) & $\begin{array}{l}\text { Number of carbapenem-non- } \\
\text { resistant isolates }\end{array}$ & $(\%)$ \\
\hline \multicolumn{7}{|l|}{ Patient visits } \\
\hline Outpatient clinics & 12,169 & & & & & \\
\hline Hospitals & 26,840 & & & & & \\
\hline Total number of isolates & 43,948 & 100 & 1,856 & 4.2 & 42,092 & 95.8 \\
\hline 2014 & 3437 & 7.82 & 261 & 14.06 & 3176 & 7.55 \\
\hline 2015 & 7660 & 17.43 & 411 & 22.14 & 7249 & 17.22 \\
\hline 2016 & 10,139 & 23.07 & 334 & 18.00 & 9805 & 23.29 \\
\hline 2017 & 11,794 & 26.84 & 470 & 25.32 & 11,324 & 26.90 \\
\hline 2018 & 10,918 & 24.84 & 380 & 20.47 & 10,538 & 25.04 \\
\hline \multicolumn{7}{|l|}{ Care setting type } \\
\hline Outpatient clinics & 13,081 & 29.76 & 171 & 9.21 & 12,910 & 30.67 \\
\hline Secondary care hospitals & 15,853 & 36.07 & 781 & 42.08 & 15,072 & 35.81 \\
\hline Tertiary care hospitals & 13,022 & 29.63 & 769 & 41.43 & 12,253 & 29.11 \\
\hline Specialist care hospitals & 1335 & 3.04 & 96 & 5.17 & 1239 & 2.94 \\
\hline $\begin{array}{l}\text { Prevention and rehabilitation } \\
\text { care centres }\end{array}$ & 390 & 0.89 & 34 & 1.83 & 356 & 0.85 \\
\hline Other hospitals & 115 & 0.26 & 1 & 0.05 & 114 & 0.27 \\
\hline Unknown hospital type & 152 & 0.35 & 4 & 0.22 & 148 & 0.35 \\
\hline \multicolumn{7}{|l|}{ German region } \\
\hline Southeast & 9327 & 21.22 & 199 & 10.72 & 9128 & 21.69 \\
\hline Southwest & 8,819 & 20.07 & 245 & 13.20 & 8,574 & 20.37 \\
\hline West & 14,945 & 34.01 & 959 & 51.67 & 13,986 & 33.23 \\
\hline Northwest & 5490 & 12.49 & 332 & 17.89 & 5158 & 12.25 \\
\hline Northeast & 4689 & 10.67 & 116 & 6.25 & 4573 & 10.86 \\
\hline NA & 678 & 1.54 & 5 & 0.27 & 673 & 1.60 \\
\hline \multicolumn{7}{|l|}{ Patient gender } \\
\hline Female & 15,884 & 36.1 & 445 & 23.98 & 15,439 & 36.68 \\
\hline Male & 19,962 & 45.42 & 1187 & 63.95 & 18,775 & 44.60 \\
\hline NA & 8102 & 18.44 & 224 & 12.07 & 7878 & 18.72 \\
\hline Sex ratio & 0.84 & & 0.45 & & 0.86 & \\
\hline \multicolumn{7}{|l|}{ Patient age } \\
\hline$<1$ year & 1651 & 3.76 & 8 & 0.43 & 1643 & 3.90 \\
\hline $1-19$ years & 2844 & 6.47 & 34 & 1.83 & 2810 & 6.68 \\
\hline 20-39 years & 3106 & 7.07 & 208 & 11.21 & 2898 & 6.88 \\
\hline $40-59$ years & 7203 & 16.39 & 417 & 22.47 & 6786 & 16.12 \\
\hline $60-79$ years & 18,496 & 42.09 & 989 & 53.29 & 17,507 & 41.59 \\
\hline$\geq 80$ years & 10,608 & 24.14 & 199 & 10.72 & 10,409 & 24.73 \\
\hline NA & 40 & 0.09 & 1 & 0.05 & 39 & 0.09 \\
\hline Age (median, IQR) & $69(52-79)$ & & $66(53-75)$ & & $69(52-79)$ & \\
\hline \multicolumn{7}{|l|}{ Clinical specimen material } \\
\hline Upper respiratory & 4107 & 9.35 & 166 & 8.94 & 3941 & 9.36 \\
\hline Lower respiratory & 3496 & 7.95 & 400 & 21.55 & 3096 & 7.36 \\
\hline Other respiratory & 443 & 1.01 & 41 & 2.21 & 402 & 0.96 \\
\hline Blood & 997 & 2.27 & 81 & 4.36 & 916 & 2.18 \\
\hline Wound & 12,254 & 27.88 & 342 & 18.43 & 11,912 & 28.30 \\
\hline Urine & 8887 & 20.22 & 203 & 10.94 & 8684 & 20.63 \\
\hline Other & 13,659 & 31.08 & 619 & 33.35 & 13,040 & 30.98 \\
\hline NA & 105 & 0.24 & 4 & 0.22 & 101 & 0.24 \\
\hline
\end{tabular}

IQR interquartile range, NA not available 
urine (20.2\%) and respiratory materials (18.3\%) (Table 1). Among the 30,867 isolates from hospitals, $5428(17.6 \%)$ were derived from intensive care units.

\section{Proportional distribution of $A$. baumannii complex species and A. baumannii}

In all clinical specimens, $60 \%$ of all Acinetobacter species were identified as species of the A. baumannii complex (Additional file 1: Fig. 1A). A. baumannii sensu stricto accounted for two-thirds of all $A$. baumannii complex isolates $(19,522$ out of 30,051 [65\%]). Among blood isolates, A. baumannii and species of the $A$. baumannii complex accounted for $26 \%$ and $44 \%$ of all Acinetobacter species, respectively (Additional file 1: Fig. 1B). In contrast, in lower respiratory materials, $A$. baumannii complex species (76\%) and $A$. baumannii sensu stricto (54\%) were the most frequent Acinetobacter species (Additional file 1: Fig. 1C).

\section{Current CRABC epidemiology in Germany}

During the study period (2014-2018), the mean proportion of CRABC in Germany was $4.2 \%$ (95\% CI 3.0$6.0 \%$ ). In 2018, the CRABC proportion was 3.5\% (95\% CI $2.5-4.7 \%)$. In contrast, only $0.9 \%$ (95\% CI $0.8-1.0 \%$ ) of non-baumannii complex Acinetobacter isolates showed carbapenem resistance between 2014 and 2018. In the same time period, proportions of carbapenem resistance also varied among species of the $A$. baumannii complex. While carbapenem resistance was more pronounced in A. baumannii sensu stricto (5.7\% [95\% CI 4.2-8.0\%]) and $A$. nosocomialis (7.0\% [95\% CI 1.7-25.0\%]), carbapenem resistance proportions were lower in $A$. pittii $(0.8 \%$ [95\% CI 0.4-1.0\%]) and A. calcoaceticus (0.6\% [95\% CI $0.2-2.0 \%])$.

\section{Care setting type}

Differences in carbapenem resistance patterns between isolates from patients treated in outpatient clinics and different types of hospital are presented in Fig. 1. Carbapenem resistance in $A$. baumannii complex isolates

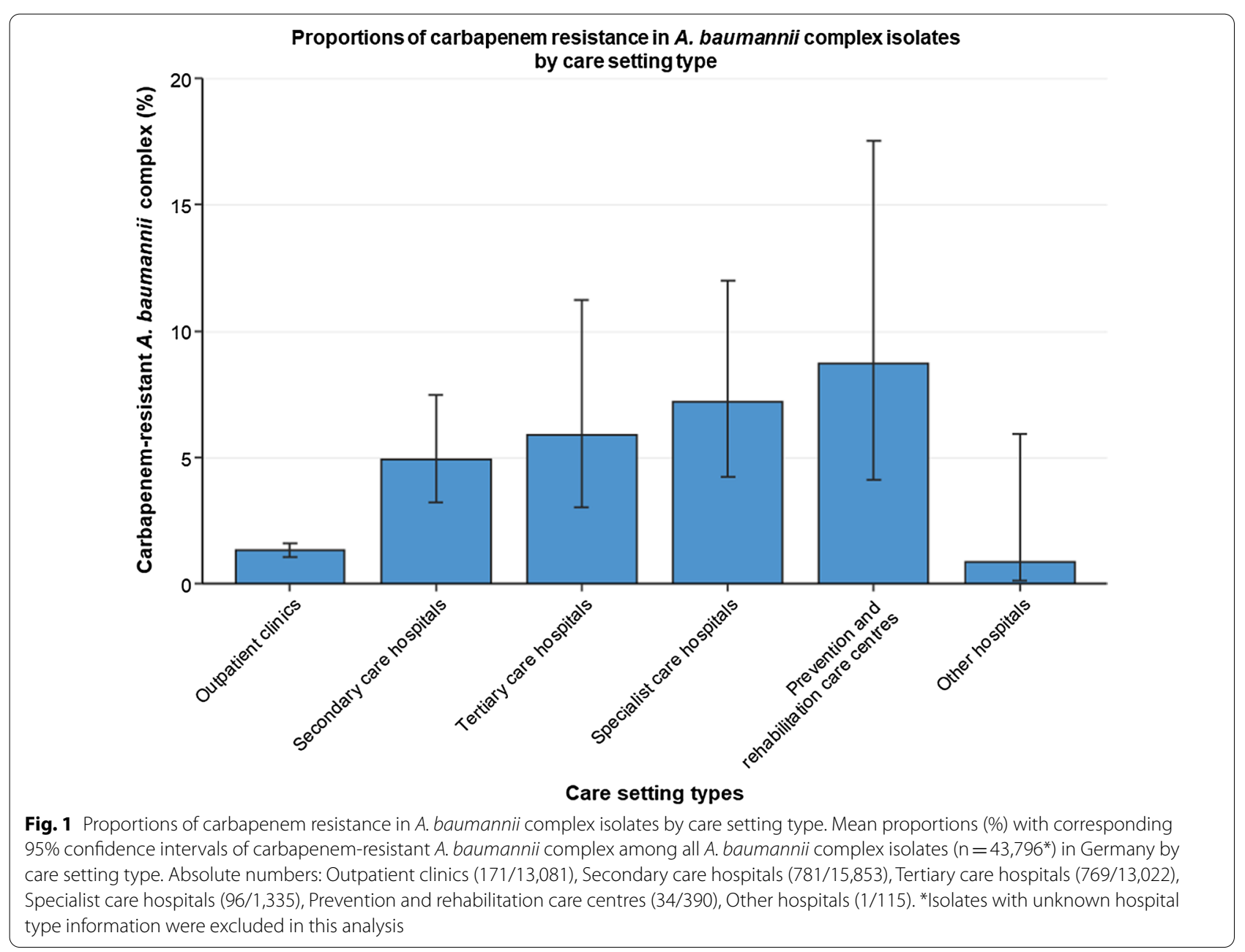


was lower among isolates from outpatient clinics $(1.3 \%$ [95\% CI 1.1-1.6\%]) compared to all types of hospitals, with CRABC proportions ranging from $4.9 \%$ (95\% CI $3.2-7.5 \%)$ in secondary care hospitals to $8.7 \%$ (95\% CI 4.1-17.5\%) in prevention and rehabilitation care centres (Fig. 1). Univariable and multivariable regression analyses confirmed that $A$. baumannii complex isolates from hospitals were more likely to be carbapenemresistant than isolates from outpatient clinics (Table 2).

\section{Temporal trends}

Between 2014 and 2018, proportions of carbapenemresistant $A$. baumannii complex in Germany decreased from $7.6 \%$ (95\% CI 4.4-12.7\%) to 3.5\% (95\% CI 2.5-4.7\%) (Fig. 2). This decreasing trend was also supported by the multivariable analysis (adjusted OR: 0.85 [95\% CI $0.79-0.93, p \leq 0.001]$ ) (Table 2 ). An additional sensitivity analysis of the temporal trend was conducted on isolates $(\mathrm{n}=22,876)$ from healthcare facilities (1700 outpatient clinics, 194 hospitals) that provided data continuously

Table 2 Analysis of factors associated with carbapenem resistance in Acinetobacter baumannii complex isolates in Germany

\begin{tabular}{|c|c|c|c|c|c|c|}
\hline & \multicolumn{3}{|c|}{ Univariable analysis } & \multicolumn{3}{|c|}{ Multivariable analysis } \\
\hline & OR & $(95 \% \mathrm{Cl})$ & $p$ value & OR & $(95 \% \mathrm{Cl})$ & $p$ value \\
\hline \multicolumn{7}{|l|}{ Year of sampling (per 1 year increase) } \\
\hline $2014-2018$ & 0.84 & $(0.77-0.91)$ & $<0.001$ & 0.85 & $(0.79-0.93)$ & $<0.001$ \\
\hline \multicolumn{7}{|l|}{ Care setting type } \\
\hline Outpatient clinics & 1 & - & - & 1 & - & - \\
\hline Secondary care hospitals & 3.91 & $(2.40-6.39)$ & $<0.001$ & 3.59 & $(2.44-5.27)$ & $<0.001$ \\
\hline Tertiary care hospitals & 4.74 & $(2.31-9.74)$ & $<0.001$ & 5.41 & $(2.93-9.99)$ & $<0.001$ \\
\hline Specialist care hospitals & 5.85 & $(3.23-10.61)$ & $<0.001$ & 7.24 & $(3.90-13.43)$ & $<0.001$ \\
\hline $\begin{array}{l}\text { Prevention and rehabilitation care } \\
\text { centres }\end{array}$ & 7.21 & $(3.21-16.17)$ & $<0.001$ & 9.58 & $(3.02-30.32)$ & $<0.001$ \\
\hline Other hospitals & 0.66 & $(0.11-4.17)$ & 0.661 & $-^{*}$ & $-{ }^{*}$ & $-^{*}$ \\
\hline \multicolumn{7}{|l|}{ German region } \\
\hline Northeast & 0.37 & $(0.19-0.73)$ & 0.004 & 0.25 & $(0.12-0.51)$ & $<0.001$ \\
\hline Southeast & 0.32 & $(0.17-0.61)$ & $<0.001$ & 0.20 & $(0.11-0.36)$ & $<0.001$ \\
\hline Southwest & 0.42 & $(0.22-0.80)$ & 0.008 & 0.31 & $(0.18-0.52)$ & $<0.001$ \\
\hline West & 1 & - & - & 1 & - & - \\
\hline Northwest & 0.94 & $(0.33-2.66)$ & 0.905 & 0.72 & $(0.37-1.40)$ & 0.338 \\
\hline \multicolumn{7}{|l|}{ Patient gender } \\
\hline Female & 1 & - & - & 1 & - & - \\
\hline Male & 2.19 & $(1.70-2.84)$ & $<0.001$ & 1.91 & $(1.55-2.36)$ & $<0.001$ \\
\hline \multicolumn{7}{|l|}{ Patient age } \\
\hline$<1$ year & 0.08 & $(0.03-0.19)$ & $<0.001$ & 0.06 & $(0.03-0.14)$ & $<0.001$ \\
\hline $1-19$ years & 0.20 & $(0.13-0.30)$ & $<0.001$ & 0.21 & $(0.17-0.38)$ & $<0.001$ \\
\hline 20-39 years & 1.17 & $(0.84-1.63)$ & 0.359 & 1.56 & $(1.10-2.23)$ & 0.014 \\
\hline 40-59 years & 1 & - & - & 1 & - & - \\
\hline $60-79$ years & 0.92 & $(0.73-1.17)$ & 0.487 & 0.96 & $(0.73-1.26)$ & 0.775 \\
\hline $80 \geq$ years & 0.31 & $(0.23-0.42)$ & $<0.001$ & 0.37 & $(0.28-0.49)$ & $<0.001$ \\
\hline \multicolumn{7}{|l|}{ Clinical specimen material } \\
\hline Upper respiratory & 1 & - & - & 1 & - & - \\
\hline Lower respiratory & 3.07 & $(2.45-3.84)$ & $<0.001$ & 1.52 & $(1.21-1.91)$ & $<0.001$ \\
\hline Other respiratory & 2.42 & $(1.42-4.13)$ & 0.001 & 1.52 & $(0.95-2.43)$ & 0.081 \\
\hline Blood & 2.10 & $(1.32-3.34)$ & 0.002 & 1.25 & $(0.91-1.73)$ & 0.167 \\
\hline Wound & 0.68 & $(0.52-0.90)$ & 0.007 & 0.44 & $(0.33-0.59)$ & $<0.001$ \\
\hline Urine & 0.55 & $(0.43-0.71)$ & $<0.001$ & 0.37 & $(0.27-0.51)$ & $<0.001$ \\
\hline Other & 1.13 & $(0.88-1.44)$ & 0.345 & 0.89 & $(0.70-1.12)$ & 0.317 \\
\hline
\end{tabular}

95\% Cl 95\% confidence interval, OR odds ratio

*Data not presented due to the very low isolate number $(n=72)$, all isolates were not resistant against carbapenems 


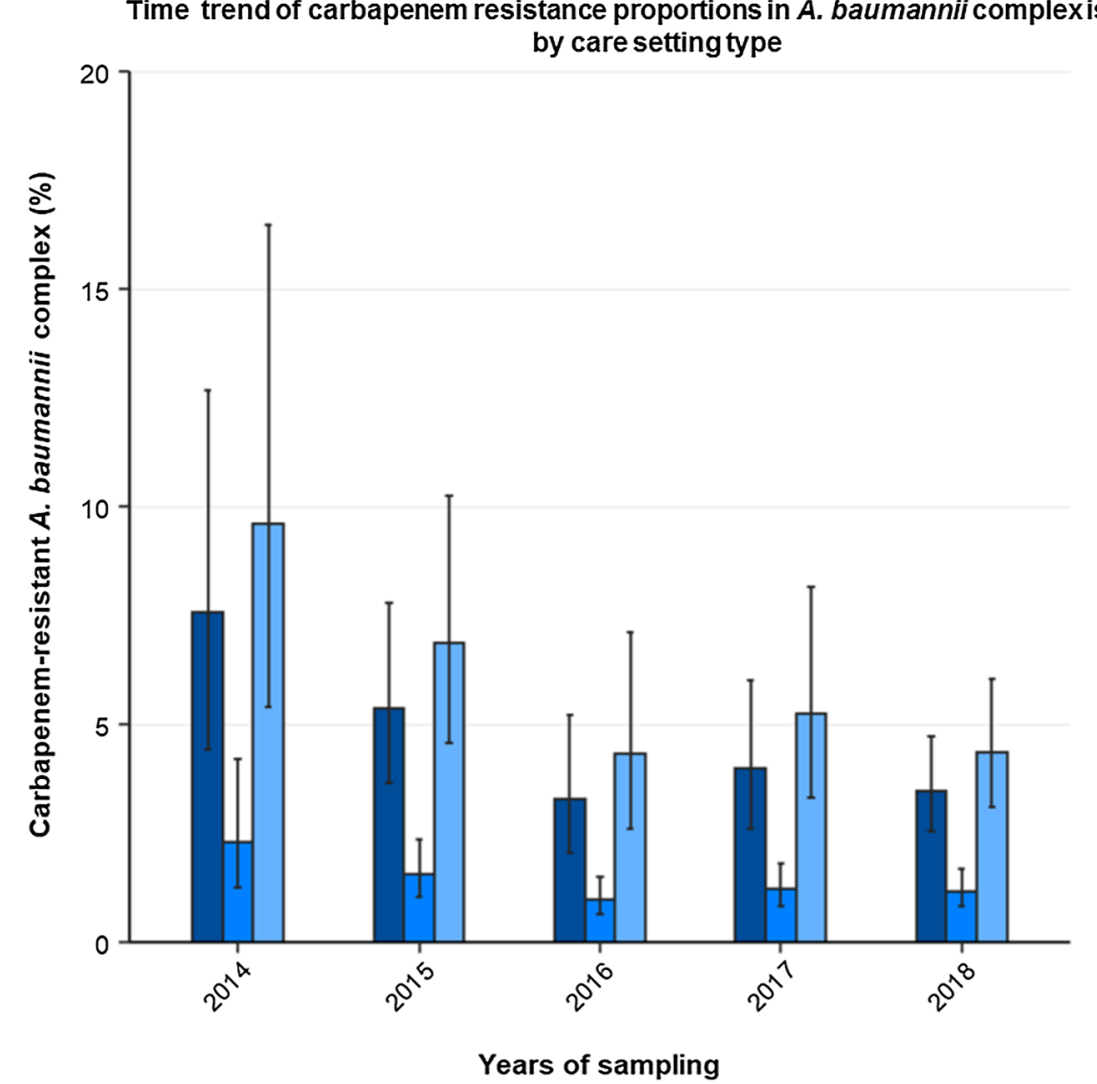

Fig. 2 Time trend of carbapenem resistance proportions in A. baumannii complex isolates by care setting type. Time trend of mean proportions (\%) with corresponding $95 \%$ confidence intervals of carbapenem-resistant $A$. baumannii complex among all A. baumannii complex isolates $(n=43,948)$ in Germany between 2014 and 2018, stratified by care setting type. Absolute numbers: Total: 2014 (261/3,437), 2015 (411/7,660), 2016 (334/10,139), 2017 (470/11,794), 2018 (380/10,918); Outpatient clinics: 2014 (22/950), 2015 (35/2,208), 2016 (32/3,187), 2017 (46/3,705), 2018 (36/3,031); Hospitals: 2014 (239/2,487), 2015 (376/5,452), $2016(302 / 6,952), 2017(424 / 8,089), 2018(344 / 7,887)$

for the entire study period (2014-2018). This sensitivity analysis showed similar temporal trends: CRABC proportions decreased from $7.8 \%$ (95\% CI $4.2-14.1 \%)$ in 2014 to $4.4 \%$ (95\% CI $2.6-7.2 \%)$ in 2018.

In addition, we found similar temporal trends in both outpatient clinics and hospitals. In isolates from outpatient clinics, proportions of carbapenem resistance declined from $2.3 \%$ (95\% CI $1.3-4.2 \%$ ) in 2014 to $1.2 \%$ (95\% CI 0.8-1.7\%) in 2018 (adjusted OR: 0.80 [95\% CI 0.66-0.97, $p \leq 0.001]$ ) (Fig. 2). In hospitals, carbapenemresistant proportions decreased from 9.6\% (95\% CI 5.4$16.5 \%$ ) to $4.4 \%$ (95\% CI 3.1-6.1\%) during the same period (adjusted OR: 0.85 [95\% CI 0.78-0.93, $p \leq 0.001]$ ).

\section{Regional analysis}

Mean CRABC proportions (2014-2018) varied between German regions, with higher CRABC proportions in the West and Northwest of Germany than the other regions (Fig. 3). The multivariable analysis confirmed that $A$. baumannii complex isolates from the Northeast, Southeast and Southwest were less likely to be resistant to carbapenems in comparison to isolates from the West (Table 2). Regional variations were most pronounced amongst hospitals, with CRABC proportions ranging between $2.4 \%$ (95\% CI 1.6-3.5\%) in the Southeast and 8.8\% (95\% CI 4.2-17.3\%) in the Northwest (Additional file 1: Fig. 2). In contrast, no geographic variation was observed amongst outpatient clinics.

\section{Age and gender}

CRABC proportions were significantly lower in young patients between $<1$ year $(0.6 \%$ [95\% CI $0.2-1.3 \%])$ and $1-19$ years (1.3\% [95\% CI $0.7-2.5 \%])$ compared to adult patients between 20 and 79 years (20-39 years: $7.7 \%$ [95\% CI $4.4-13.0 \%$ ]; $40-59$ years: $6.2 \%$ [95\% CI $4.2-8.9 \%$ ]; 60-79 years: $5.8 \%$ [95\% CI 4.0-8.3\%]). Patients older than 79 years showed lower proportions (1.9\% [95\% CI 1.3$2.7 \%]$ ) than patients between 20 and 79 years. The lower likelihood of carbapenem resistance among patients aged 80 years and older compared to those between 40 and 


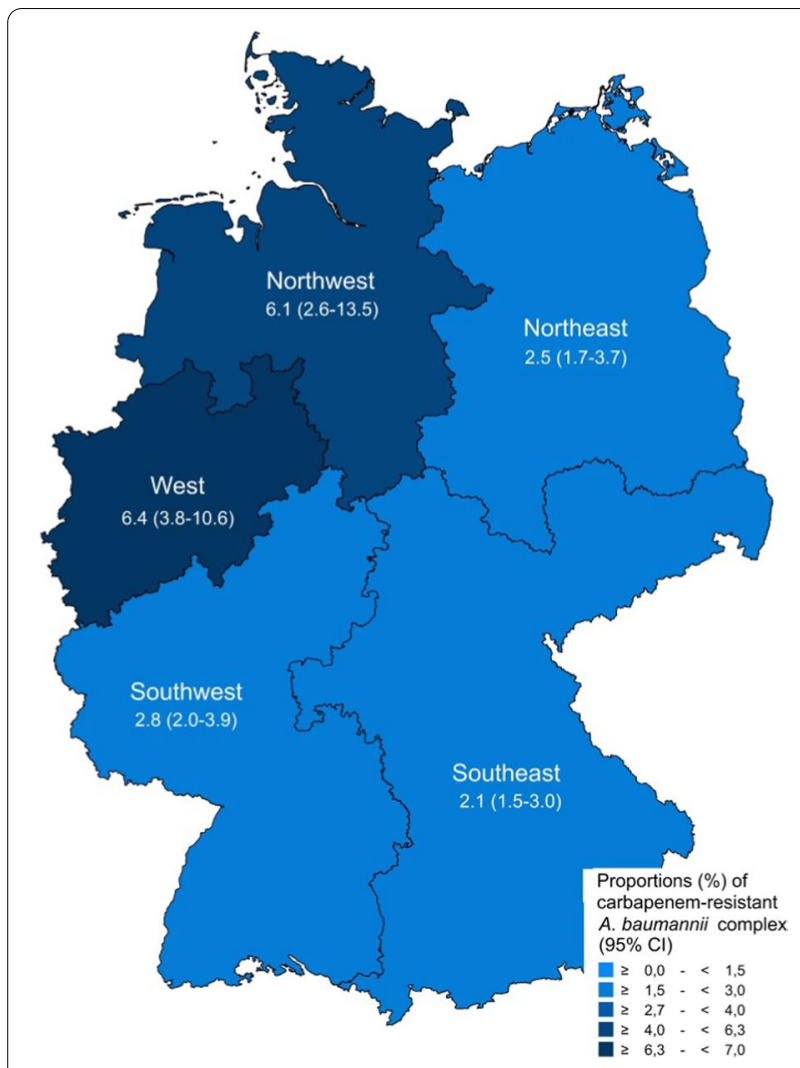

Fig. 3 Regional distribution of carbapenem resistance proportions in A. baumannii complex isolates. Distribution of A. baumannii complex with carbapenem resistance in German regions, expressed as mean proportions (\%) among all A. baumannii complex isolates $\left(n=43,270^{*}\right)$ and with corresponding 95\% confidence intervals. Absolute numbers: Northeast (116/4,689), Southeast (199/9,327), Southwest $(245 / 8,819)$, West $(959 / 14,945)$, Northwest $(332 / 5,490)$. *Only isolates with complete information on regional origin were included in this analysis

59 years was also confirmed by the multivariable analysis (Table 2). Moreover, we identified male gender as an independent risk factor for carbapenem resistance in A. baumannii complex isolates (adjusted OR: 1.91 [95\% CI $1.55-2.36, p \leq 0.001]$ ). Differences in proportions between genders were especially pronounced in patients between 20 and 39 years (Men: 14.6\% [95\% CI 8.6-23.6\%] vs. Women: $2.5 \%$ [95\% CI $1.3-4.5 \%]$ ). In contrast, we found no variations in proportions between male and female patients in people younger than 20 years or for those 80 years and older (Fig. 4).

\section{Clinical specimen material}

Our data show that $A$. baumannii complex isolates from lower respiratory samples (11.4\% [95\% CI 7.9-16.2\%]) exhibited higher carbapenem resistance proportions than isolates from upper respiratory material $(4.0 \%$ [95\% CI $2.7-6.0 \%])$, urine (2.3\% [95\% CI $1.6-3.3 \%])$ and wound
(2.8\% [95\% CI 2.0-3.9\%]) (Fig. 5). This was also confirmed by the multivariable analysis (Table 2). Although our data indicate that blood isolates had higher CRABC proportions (8.1\% [95\% CI 4.4-14.6\%]) than upper respiratory samples, the multivariable analysis did not indicate statistical significance (adjusted OR: 1.25 [95\% CI $0.91-1.73, p=0.162])$.

\section{Discussion}

Carbapenem resistance in A. baumannii complex isolates from hospitalised patients in Germany was $4.4 \%$ in 2018 , which is significantly lower than those recently observed in hospitals in other regions across the world such as North America (44\%) [18], Latin American (50-90\%) [18, 33, 34] and the Asia-Pacific region (79\%) [18]. In China and Saudi Arabia, $71.0 \%$ and $60.0 \%$ of Acinetobacter isolates from hospitalised patients were found to be carbapenem-resistant, respectively [35, 36].

Similar to the situation in Germany described in this study, Norway, Slovenia, and Portugal also reported decreasing carbapenem resistance in Acinetobacter species [26]. In the United States, the number of estimated cases among hospitalised patients infected with carbapenem-resistant $A$. baumannii declined from 11,700 to 8500 between 2012 and 2017 [25]. However, rising carbapenem resistance among Acinetobacter species were observed in other countries, such as the Czech Republic, Slovakia, Croatia [26] and China [35], highlighting its persisting clinical significance and importance of continuous surveillance. One possible reason for a declining trend in some countries, such as in Norway, Slovenia and the USA, is their adoption of national strategies in recent years with established targets to reduce antibiotic consumption, which is not the case for Slovakia and Croatia [37]. In Germany, the German Antibiotic Resistance Strategy includes several measures to limit antibiotic resistance, such as training courses in antibiotic stewardship as well as the implementation and promotion of surveillance systems [38].

Despite the decreasing trends found in our study, the analysis also revealed that proportions of CRABC are higher in German hospitals compared to outpatient clinics. Carbapenems are reserve antibiotics with a broad activity spectrum and are mainly used in hospitalised patients with serious illnesses such as sepsis or lower respiratory tract infections [39]. Several previous studies have found that the use of carbapenems is correlated with carbapenem resistance in hospitals [40-43]. In Germany, it has been shown that an increase in the use of carbapenems was associated with a rise in carbapenem resistance in A. baumannii in ICUs between 2001 and 2015 [44]. Another possible reason for higher proportions of CRABC in hospitals is the higher number of 


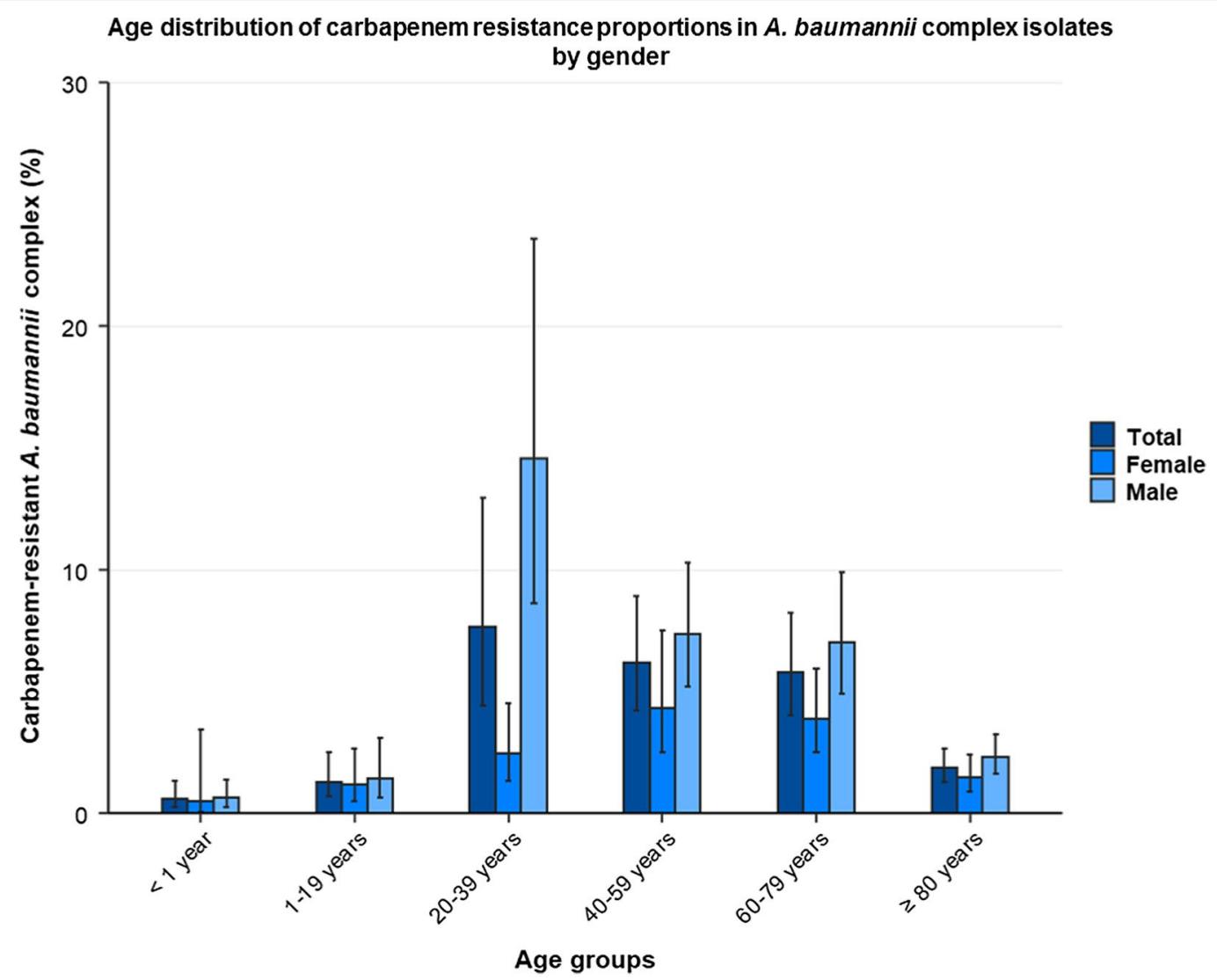

Fig. 4 Age distribution of carbapenem resistance proportions in A. baumannii complex isolates by gender. Age distribution of mean proportions (\%) with corresponding 95\% confidence intervals of carbapenem-resistant $A$. baumannii complex among all A. baumannii complex isolates $\left(n=35,821^{*}\right)$ stratified by gender, expressed as mean proportions. Absolute numbers: Total: $<1$ year $(8 / 1,390), 1-19$ years $(31 / 2,379), 20-39$ years (196/2,560), 40-59 years (365/5,911), 60-79 years (873/15,054), $80 \geq$ years (159/8,527); Female: $<1$ year $(3 / 587), 1-19$ years $(14 / 1,201), 20-39$ years $(36 / 1,463), 40-59$ years $(101 / 2,324), 60-79$ years $(225 / 5,812), 80 \geq$ years $(66 / 4,491)$; Male: $<1$ year $(5 / 803), 1-19$ years $(17 / 1,178), 20-39$ years $(160 / 1,097), 40-59$ years $(264 / 3,587), 60-79$ years $(648 / 9,242), 80 \geq$ years $(93 / 4,036)$. ${ }^{*}$ Only isolates with complete information on gender and age were included in this analysis

co-morbidities of hospitalised patients, which are associated with antibiotic resistance, compared to patients in outpatient clinics [45].

Our data also indicate regional differences in CRABC proportions in Germany: In the North-western and Western regions, significantly higher proportions of resistance were observed than in the other regions in Germany. These differences were mainly observed in isolates from hospitals. One possible explanation for this might be regional differences in hospital usage of carbapenems. However, this has not yet been evidenced in any publications. Although there are national guidelines for the management of infections/colonisation with multi-resistant Gram-negative rods, including Acinetobacter [46], the implementation of infection prevention and control and antibiotic stewardship strategies are regulated differently by the 16 federal states and between hospitals, which may also contribute to the regional differences. Interestingly, large regional differences in carbapenem resistance in Acinetobacter isolates have also been observed at the European level, where resistance proportions are particularly high in Southern and Eastern European countries $[26,47]$. This might be explained by the implementation of antibiotic stewardship programmes and strategies for infection prevention and control in some areas, which are effective against carbapenemresistant $A$. baumannii infections and other pathogens [25, 48, 49]. Regional CRABC proportions might also be influenced by local CRABC hospital outbreaks and spreads of CRABC strains. However, the reasons for the observed regional differences should be investigated in further studies that assess potential risk factors among hospital patients, such as previous carbapenem exposure and stays in countries with a high prevalence of carbapenem resistance. 


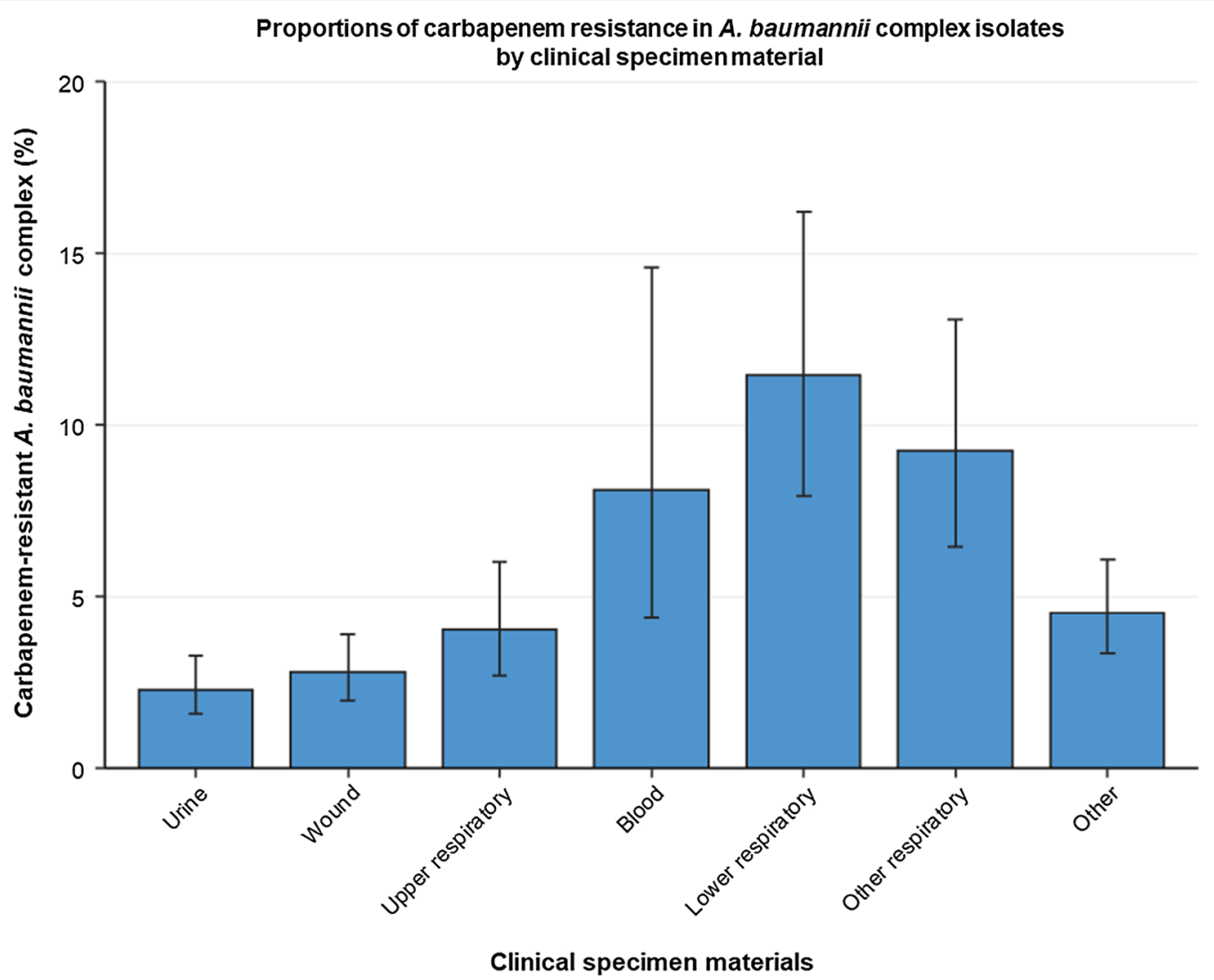

Fig. 5 Proportions of carbapenem resistance in A. baumannii complex isolates by clinical specimen material. Mean proportions (\%) with corresponding 95\% confidence intervals of carbapenem-resistant A.baumannii complex among all A. baumannii complex isolates $\left(n=43,843^{*}\right)$, stratified into clinical specimen materials. Absolute numbers: Urine (203/8,887), Wound (342/12,254), Upper respiratory (166/4,107), Blood (81/997), Lower respiratory $(400 / 3,496)$, Other respiratory $(41 / 443)$, Other $(619 / 13,659)$. ${ }^{*}$ Only isolates with complete information on clinical specimen material were included in this analysis

We also observed that carbapenem resistance is more likely to be found in A. baumannii complex isolates from patients between 20 and 70 years than in isolates from children, adolescents and patients who are 80 years or older. Similarly, there was also a higher likelihood of resistance in middle aged adults and elderly patients in other pathogens, including carbapenem-resistant Enterobacteriaceae [50], carbapenem non-susceptible Klebsiella pneumoniea [51] and vancomycin-resistant Enterococcus faecium [52, 53]. Older patients are more likely to be affected by antimicrobial resistance since the probability of being colonised or infected with resistant pathogens increases with each exposure to antibiotics over the course of their lifetime. However, why the very elderly ( $\geq 80$ years) show profoundly less carbapenem resistance proportions remains unclear and could be addressed in further studies. Interestingly, our data identified clear differences between men and women in CRABC proportions in adults aged 20 to 39. In this age group, carbapenem resistance in A. baumannii complex isolates from men were significantly higher than in isolates from women (14.6\% vs. $2.5 \%)$. A similar observation has already been described for carbapenem-non-susceptible Klebsiella pneumoniae in Germany, although the reasons for this observation remain unknown [51]. Studies have suggested that hormonal differences in this age group may be responsible for immune advantages against infectious diseases amongst women [54]. However, whether this explains the observed gender distribution of antibiotic resistant infections is unknown and should be addressed in further studies.

Furthermore, our study revealed high proportions of CRABC in blood isolates (8.1\%) and lower respiratory materials (11.4\%). Higher proportions of resistance in blood isolates $(7.6 \%)$ in comparison to other clinical specimen materials have also been reported in multidrug-resistant $A$. baumannii isolates among hospitalised patients in Germany between 2002 and 2006 [55]. Blood isolates and lower respiratory materials most likely represent more severe diseases, such as bloodstream infections 
and pneumonia which often require fast empirical antibiotic therapies. Hence, increased carbapenem resistance limits the therapeutic effectiveness of empirical carbapenem treatment in those patients.

Our study also revealed that in all clinical specimen materials, $A$. baumannii sensu stricto accounted for $65 \%$ of all $A$. baumannii complex species, which is much lower than the commonly-assumed proportion of over $90 \%$ in Europe [56]. In line with our findings, a study from France showed that only $40 \%$ of all A. baumannii complex bloodstream infections were associated with A. baumannii sensu stricto [57]. Interestingly, our data also indicate that species of the A. baumannii complex only accounted for $60 \%$ of all isolated Acinetobacter species. A. baumannii complex proportions were even lower (44\%) in Acinetobacter bloodstream isolates. Similar results were also found in a study from Japan, where A. baumannii complex species accounted for $52 \%$ of all Acinetobacter isolates identified in patients with bacteraemia [58]. In contrast, other studies have shown that $A$. baumannii complex species are the predominant species in clinical Acinetobacter bloodstream infections [59, 60]. These conflicting results indicate that Acinetobacter species distribution may be locally very different.

Our finding of substantial differences in carbapenem resistance proportions among the different Acinetobacter species suggests that estimates for carbapenem resistance in clinical Acinetobacter isolates are largely dependent on the proportion of individual A. baumannii complex and non-baumannii complex Acinetobacter species. As a result, our study emphasises the importance of identifying Acinetobacter isolates with associated carbapenem resistances at the species level in order to fully understand the extent of carbapenem resistance in Acinetobacter infections.

\section{Strengths and limitations}

To our knowledge, this study is the most comprehensive analysis of the current epidemiology and risk factors of carbapenem resistance in A. baumannii complex isolates in Germany. Based on data from the German ARS system, we analysed almost 44,000 clinical A. baumannii complex isolates from more than 39,000 patient visits in hospitals and outpatient clinics.

Our study is also subject to several limitations. Firstly, since no information on diagnoses is available in the ARS database, it can only be assumed that the clinical specimens represent infectious diseases. Although we excluded all isolates labelled as screening samples, it is also possible that some of the included isolates (e.g. swabs of upper respiratory materials) actually represent screening samples that were not assigned as such by the hospital or laboratory [51]. Secondly, because participation in the ARS system is voluntary, the coverage of healthcare facilities providing ARS data may differs across regions and may not be representative. However, numbers of isolates from the analysed German regions roughly reflect population sizes in these regions. Finally, no clinical information is available in the ARS system, such as use of medical devices and co-morbidities, which are known to be associated with carbapenem resistance in $A$. baumannii complex infections.

\section{Conclusion}

Infections with carbapenem-resistant $A$. baumannii complex are a major public health threat in health care settings worldwide. In contrast to many other regions worldwide, carbapenem resistance proportions among clinical A. baumannii complex isolates are relatively low in Germany and have declined in the last years. However, higher CRABC proportions were observed in hospitals in the West and Northwest of Germany and among young men for which the underlying reasons should be investigated in further studies. Continuous efforts in antibiotic stewardship and infection prevention and control measures are needed to prevent the spread of $C R A B C$ in Germany.

\section{Supplementary Information}

The online version contains supplementary material available at https://doi. org/10.1186/s13756-021-00909-8.

Additional file 1: Figure 1. Proportional distribution of Acinetobacter species. Figure 2. Regional distribution of carbapenem resistance proportions in A. baumannii complex isolates by care setting type

\section{Abbreviations \\ aOR: Adjusted odds ratio; ARS: Antimicrobial Resistance Surveillance; CDC: Centers for Disease Control and Prevention; CLSI: Clinical and Laboratory Standards Institute; CRABC: Carbapenem-resistant Acinetobacter baumannii complex; EARS-Net: European Antimicrobial Resistance Surveillance Network; EUCAST: European Committee on Antimicrobial Susceptibility Testing; ICU: Intensive care unit; IQR: Interquartile range; OR: Odds ratio; R: Resistant; RKI: Robert Koch Institute; WHO: World Health Organization; 95\% Cl: 95\% Confi- dence interval.}

\section{Acknowledgements}

We thank all the laboratories and hospitals for contributing data to this analysis. We thank our colleagues at the Robert Koch Institute for their input during this study, namely, Angelina Taylor, Hans-Peter Blank, Marcel Feig and Sebastian Haller.

\section{Authors' contributions}

DS, RM, OA, and TE were responsible for conceptualisation of the study and formulation of the research goals and aims. NW and RM developed the methodology and models. IN established and maintains the ARS database and continuously validates the data. DS and RM performed the statistical analysis. DS and RM wrote the original draft. All authors reviewed and commented the draft and gave input on editing. All authors read and approved the final manuscript. 


\section{Funding}

Open Access funding enabled and organized by Projekt DEAL. The analysis was supported by the Robert Koch Institute's internal funds. The institute is a Federal Institute within the portfolio of the German Ministry of Health.

\section{Availability of data and materials}

Aggregated ARS data are available online (https://ars.rki.de). All raw data can be provided on reasonable request.

\section{Ethics approval and consent to participate}

The study only includes routine surveillance data. Ethical approval for analysis of such surveillance data is not required according to the Medical Association's professional code of conduct.

\section{Consent for publication}

Not applicable.

\section{Competing interests}

The authors declare that they have no competing interests.

\section{Author details}

${ }^{1}$ Department 3: Infectious Disease Epidemiology, Unit 37: Healthcare Associated Infections, Surveillance of Antibiotic Resistance and Consumption, Robert Koch Institute, Nordufer 20, 13353 Berlin, Germany. ${ }^{2}$ Institute of General Practice and Family Medicine, Jena University Hospital, Bachstraße 18, 07743 Jena, Germany.

Received: 21 July 2020 Accepted: 12 February 2021

Published online: 01 March 2021

\section{References}

1. Nemec A, Krizova L, Maixnerova M, van der Reijden TJK, Deschaght P, Passet $V$, et al. Genotypic and phenotypic characterization of the Acinetobacter calcoaceticus-Acinetobacter baumannii complex with the proposal of Acinetobacter pittii sp. nov. (formerly Acinetobacter genomic species 3) and Acinetobacter nosocomialis sp. nov. (formerly Acinetobacter genomic species 13TU). Res Microbiol. 2011;162(4):393-404

2. Al Atrouni A, Joly-Guillou ML, Hamze M, Kempf M. Reservoirs of nonbaumannii Acinetobacter species. Front Microbiol. 2016;7:49.

3. Nemec A. Classification and nomenclature of species in the genus Acinetobacter; 2020. https://apps.szu.cz/anemec/Classification.pdf.

4. Peleg AY, Seifert H, Paterson DL. Acinetobacter baumannii: emergence of a successful pathogen. Clin Microbiol Rev. 2008;21(3):538-82.

5. Centers for Disease Control and Prevention. Acinetobacter baumannii infections among patients at military medical facilities treating injured US service members, 2002-2004. MMWR Morb Mortal Wkly Rep. 2004;53(45):1063.

6. Davis KA, Moran KA, McAllister CK, Gray PJ. Multidrug-resistant Acinetobacter extremity infections in soldiers. Emerg Infect Dis. 2005;11(8):1218-24

7. Jawad A, Seifert H, Snelling AM, Heritage J, Hawkey PM. Survival of Acinetobacter baumannii on dry surfaces: comparison of outbreak and sporadic isolates. J Clin Microbiol. 1998;36(7):1938-41.

8. Weber DJ, Rutala WA, Miller MB, Huslage K, Sickbert-Bennett E. Role of hospital surfaces in the transmission of emerging health care-associated pathogens: norovirus, Clostridium difficile, and Acinetobacter species. Am J Infect Control. 2010;38(5 Suppl 1):S25-33.

9. Raro OHF, Gallo SW, Ferreira CAS, Oliveira SD. Carbapenem-resistant Acinetobacter baumannii contamination in an intensive care unit. Rev Soc Bras Med Trop. 2017;50(2):167-72

10. Ayobami O, Willrich N, Harder T, Okeke IN, Eckmanns T, Markwart R. The incidence and prevalence of hospital-acquired (carbapenemresistant) Acinetobacter baumannii in Europe, Eastern Mediterranean and Africa: a systematic review and meta-analysis. Emerg Microbes Infect. 2019;8(1):1747-59.

11. Lynch JP 3rd, Zhanel GG, Clark NM. Infections due to Acinetobacter baumannii in the ICU: treatment options. Semin Respir Crit Care Med. 2017:38(3):311-25.
12. Fournier PE, Richet $H$, Weinstein RA. The epidemiology and control of Acinetobacter baumannii in health care facilities. Clin Infect Dis. 2006;42(5):692-9.

13. Dijkshoorn $L$, Nemec A, Seifert $H$. An increasing threat in hospitals: multidrug-resistant Acinetobacter baumannii. Nat Rev Microbiol. 2007;5(12):939-51.

14. Paton R, Miles RS, Hood J, Amyes SGB, Miles RS, Amyes SGB. ARI 1: $\beta$-lactamase-mediated imipenem resistance in Acinetobacter baumannii. Int J Antimicrob Agents. 1993:2(2):81-7.

15. Go ES, Urban C, Burns J, Kreiswirth B, Eisner W, Mariano N, et al. Clinical and molecular epidemiology of acinetobacter infections sensitive only to polymyxin B and sulbactam. Lancet (London, England). 1994;344(8933):1329-32.

16. Wood CA, Reboli AC. Infections caused by imipenem-resistant Acinetobacter calcoaceticus biotype anitratus. J Infect Dis. 1993;168(6):1602-3.

17. Joly-Guillou ML, Bergogne-Berezin E, Vieu JF. A study of the relationships between antibiotic resistance phenotypes, phage-typing and biotyping of 117 clinical isolates of Acinetobacter spp. J Hosp Infect. 1990;16(1):49-58

18. Gales AC, Seifert H, Gur D, Castanheira M, Jones RN, Sader HS. Antimicrobial susceptibility of Acinetobacter calcoaceticus-Acinetobacter baumannii complex and Stenotrophomonas maltophilia clinical isolates: results from the SENTRY antimicrobial surveillance program (1997-2016). Open Forum Infect Dis. 2019;6(Suppl 1):34-46.

19. Kempf M, Rolain J-M. Emergence of resistance to carbapenems in Acinetobacter baumannii in Europe: clinical impact and therapeutic options. Int J Antimicrob Agents. 2012;39(2):105-14.

20. Howard A, O'Donoghue M, Feeney A, Sleator RD. Acinetobacter baumannii. Virulence. 2012;3(3):243-50.

21. Lemos EV, La Hoz FP, Einarson TR, McGhan W, Quevedo E, Castañeda C, et al. Carbapenem resistance and mortality in patients with Acinetobacter baumannii infection: systematic review and meta-analysis. Clin Microbiol Infect. 2014;20(5):416-23.

22. Tal-Jasper R, Katz DE, Amrami N, Ravid D, Avivi D, Zaidenstein R, et al. Clinical and epidemiological significance of carbapenem resistance in Acinetobacter baumannii infections. Antimicrob Agents Chemother. 2016;60(5):3127-31.

23. Cassini A, Diaz Högberg L, Plachouras D, Quattrocchi A, Hoxha A, Simonsen GS, et al. Attributable deaths and disability-adjusted life-years caused by infections with antibiotic-resistant bacteria in the EU and the European Economic Area in 2015: a population-level modelling analysis. Lancet Infect Dis. 2019;19(1):56-66.

24. Tacconelli E, Magrini N, Kahlmeter G, Singh N. Global priority list of antibiotic-resistant bacteria to guide research, discovery, and development of new antibiotics. Geneva: World Health Organization; 2017.

25. Centers for Disease Control and Prevention. Antibiotic resistance threats in the United States 2019. Atlanta: CDC; 2019.

26. European Centre for Disease Prevention and Control. Surveillance of antimirobial resistance in Europe 2018. Stockholm: ECDC; 2019.

27. Antibiotika-Resistenz-Surveillance. ARS-antibiotika-resistenz-surveillance: Robert Koch-Institut; 2020. https://ars.rki.de/.

28. Noll I, Schweickert B, Abu Sin M, Feig M, Claus H, Eckmanns T. Daten zur Antibiotikaresistenzlage in Deutschland. Vier Jahre Antibiotika-ResistenzSurveillance (ARS). Bundesgesundheitsblatt Gesundheitsforschung Gesundheitsschutz. 2012:55(11-12):1370-6.

29. Antibiotika-Resistenz-Surveillance. Robert Koch Institut; 2019. https://ars. rki.de/Docs/Publication2019.pdf.

30. Nicolau DP. Carbapenems: a potent class of antibiotics. Expert Opin Pharmacother. 2008;9(1):23-37.

31. Team RC. R: a language and environment for statistical computing. $R$ Foundation for Statistical Computing; 2019. https://www.R-project.org/.

32. Lumley T. Package 'survey': analysis of complex survey samples; 2020

33. Labarca JA, Salles MJC, Seas C, Guzmán-Blanco M. Carbapenem resistance in Pseudomonas aeruginosa and Acinetobacter baumannii in the nosocomial setting in Latin America. Crit Rev Microbiol. 2014;27(2):1-17.

34. Garza-González E, Franco-Cendejas R, Morfín-Otero R, Echaniz-Aviles G, Rojas-Larios F, Bocanegra-lbarias $\mathrm{P}$, et al. The evolution of antimicrobial resistance in mexico during the last decade: results from the INVIFAR group. Microb Drug Resist. 2020;26:1372-82.

35. Hu F, Zhu D, Wang F, Wang M. Current status and trends of antibacterial resistance in China. Clin Infect Dis. 2018;67(suppl_2):S128-34. 
36. Balkhy HH, El-Saed A, Alshamrani MM, Alsaedi A, Al Nasser W, El Gammal $A$, et al. Ten-year resistance trends in pathogens causing healthcareassociated infections; reflection of infection control interventions at a multi-hospital healthcare system in Saudi Arabia, 2007-2016. Antimicrob Resist Infect Control. 2020;9(1):21.

37. D'Atri F, Arthur J, Blix HS, Hicks LA, Plachouras D, Monnet DL, et al. Targets for the reduction of antibiotic use in humans in the Transatlantic Taskforce on Antimicrobial Resistance (TATFAR) partner countries. Euro Surveill. 2019;24(28):2.

38. Deutsche Antibiotika-Resistenzstrategie. DART 2020 Antibiotika-Resistenzen bekämpfen zum Wohl von Mensch und Tier. Die Bundesregierung, Berlin; 2015.

39. Bradley JS, Garau J, Lode H, Rolston KVI, Wilson SE, Quinn JP. Carbapenems in clinical practice: a guide to their use in serious infection. Int J Antimicrob Agents. 1999;11(2):93-100.

40. Xu J, Sun Z, Li Y, Zhou Q. Surveillance and correlation of antibiotic consumption and resistance of Acinetobacter baumannii complex in a tertiary care hospital in northeast China, 2003-2011. Int J Environ Res Public Health. 2013;10(4):1462-73.

41. Tan C-K, Tang H-J, Lai C-C, Chen Y-Y, Chang P-C, Liu W-L. Correlation between antibiotic consumption and carbapenem-resistant Acinetobacter baumannii causing health care-associated infections at a hospital from 2005 to 2010. J Microbiol Immunol Infect. 2015;48(5):540-4.

42. Yang $P$, Chen $Y$, Jiang $S$, Shen $P$, Lu X, Xiao Y. Association between antibiotic consumption and the rate of carbapenem-resistant Gram-negative bacteria from China based on 153 tertiary hospitals data in 2014. Antimicrob Resist Infect Control. 2018;7(1):1-7.

43. Zeng $S$, Xu Z, Wang X, Liu W, Qian L, Chen X, et al. Time series analysis of antibacterial usage and bacterial resistance in China: observations from a tertiary hospital from 2014 to 2018. Infect Drug Resist. 2019;12:2683-91.

44. Remschmidt C, Schneider S, Meyer E, Schroeren-Boersch B, Gastmeier P, Schwab F. Surveillance of antibiotic use and resistance in intensive care units (SARI). Dtsch Arztebl Int. 2017;114(50):858-65.

45. Laudisio A, Marinosci F, Gemma A, Bartoli IR, Montenegro N, Incalzi RA. The burden of comorbidity is associated with antibiotic resistance among institutionalized elderly with urinary infection: a retrospective cohort study in a single Italian nursing home between 2009 and 2014 Microb Drug Resist. 2017;23(4):500-6.

46. Commission on Hospital Hygiene and Infection Protection. Hygienemaßnahmen bei Infektionen oder Besiedlung mit multiresistenten gramnegativen Stäbchen. Bundesgesundheitsblatt - Gesundheitsforschung - Gesundheitsschutz. 2012;55(10):1311-54.

47. Ayobami O, Willrich N, Suwono B, Eckmanns T, Markwart R. The epidemiology of carbapenem-non-susceptible Acinetobacter species in Europe: analysis of EARS-Net data from 2013 to 2017. Antimicrob Resist Infect Control. 2020;9(1):89.

48. Russell DL, Uslan DZ, Rubin ZA, Grogan TR, Martin EM. Multidrug resistant Acinetobacter baumanii: a 15-year trend analysis. Infect Control Hosp Epidemiol. 2018;39(5):608-11.
49. World Health Organization. Guidelines for the prevention and control of carbapenem-resistant Enterobacteriaceae, Acinetobacter baumannii and Pseudomonas aeruginosa in health care facilities. Geneva; 2017.

50. Guh AY, Bulens SN, Mu Y, Jacob JT, Reno J, Scott J, et al. Epidemiology of carbapenem-resistant enterobacteriaceae in 7 US communities, 2012-2013. JAMA. 2015;314(14):1479-87.

51. Koppe U, Laer AV, Kroll LE, Noll I, Feig M, Schneider M, et al. Carbapenem non-susceptibility of Klebsiella pneumoniae isolates in hospitals from 2011 to 2016, data from the German Antimicrobial Resistance Surveillance (ARS). Antimicrob Resist Infect Control. 2018;7(1):1-12.

52. Markwart R, Willrich N, Haller S, Noll I, Koppe U, Werner G, et al. The rise in vancomycin-resistant Enterococcus faecium in Germany: data from the German Antimicrobial Resistance Surveillance (ARS). Antimicrob Resist Infect Control. 2019;8(147):1-11.

53. Ayobami O, Willrich N, Reuss A, Eckmanns T, Markwart R. The ongoing challenge of vancomycin-resistant Enterococcus faecium and Enterococcus faecalis in Europe: an epidemiological analysis of bloodstream infections. Emerg Microbes Infect. 2020;9(1):1180-93.

54. Giefing-Kröll C, Berger P, Lepperdinger G, Grubeck-Loebenstein B. How sex and age affect immune responses, susceptibility to infections, and response to vaccination. Aging Cell. 2015;14(3):309-21.

55. Wadl M, Heckenbach K, Noll I, Ziesing S, Pfister W, Beer J, et al. Increasing occurrence of multidrug-resistance in Acinetobacter baumannii isolates from four German University Hospitals, 2002-2006. Infection. 2010;38(1):47-51.

56. European Centre for Disease Prevention and Control. Carbapenem-resistant Acinetobacter baumannii in healthcare settings-8 December 2016: rapid risk assesment. Stockholm: ECDC; 2016.

57. Pailhoriès $H$, Tiry $C$, Eveillard $M$, Kempf $M$. Acinetobacter pittii isolated more frequently than Acinetobacter baumannii in blood cultures: the experience of a French hospital. J Hosp Infect. 2018;99(3):360-3.

58. Endo S, Yano H, Kanamori H, Inomata S, Aoyagi T, Hatta M, et al. High frequency of Acinetobacter soli among Acinetobacter isolates causing bacteremia at a tertiary hospital in Japan. J Clin Microbiol. 2014;52(3):911-5.

59. Karah N, Haldorsen B, Hegstad K, Simonsen GS, Sundsfjord A, Samuelsen $\varnothing$. Species identification and molecular characterization of Acinetobacter spp. blood culture isolates from Norway. J Antimicrob Chemother. 2011;66(4):738-44.

60. Wisplinghoff $H$, Paulus T, Lugenheim M, Stefanik D, Higgins PG, Edmond $\mathrm{MB}$, et al. Nosocomial bloodstream infections due to Acinetobacter baumannii, Acinetobacter pittii and Acinetobacter nosocomialis in the United States. J Infect. 2012;64(3):282-90.

\section{Publisher's Note}

Springer Nature remains neutral with regard to jurisdictional claims in published maps and institutional affiliations.
Ready to submit your research? Choose BMC and benefit from:

- fast, convenient online submission

- thorough peer review by experienced researchers in your field

- rapid publication on acceptance

- support for research data, including large and complex data types

- gold Open Access which fosters wider collaboration and increased citations

- maximum visibility for your research: over $100 \mathrm{M}$ website views per year

At BMC, research is always in progress.

Learn more biomedcentral.com/submissions 